\title{
Survival Trends in Gastric Adenocarcinoma: A Population-Based Study in Sweden
}

\author{
Johannes Asplund, $\mathrm{MD}^{1}$, Joonas H. Kauppila, $\mathrm{PhD}^{1,2}$, Fredrik Mattsson, BSc ${ }^{1}$, and Jesper Lagergren, $\mathrm{PhD}^{1,3}$ \\ ${ }^{1}$ Upper Gastrointestinal Surgery, Department of Molecular Medicine and Surgery, Karolinska University Hospital, \\ Karolinska Institutet, Stockholm, Sweden; ${ }^{2}$ Cancer and Translational Medicine Research Unit, Medical Research Center \\ Oulu, Oulu University Hospital, University of Oulu, Oulu, Finland; ${ }^{3}$ School of Cancer and Pharmaceutical Sciences, \\ King's College London and Guy's and St Thomas' NHS Foundation Trust, London, UK
}

\begin{abstract}
Background. Gastric adenocarcinoma is the second most common cancer-related death globally. Assessing survival trends can help evaluate changes in detection and treatment. We aimed to determine recent prognosis trends in gastric non-cardia and cardia adenocarcinoma in an unselected cohort with complete follow-up.
\end{abstract}

Methods. Population-based nationwide cohort study, including 17,491 patients with gastric non-cardia adenocarcinoma and 4698 with cardia adenocarcinoma recorded in the Swedish Cancer Registry in 1990-2013 with followup until 2017. Observed and relative 5-year survival was calculated and stratified by resectional surgery and no such surgery. Prognostic factors were evaluated using multivariable Cox regression.

Results. The relative overall 5-year survival remained stable at $18 \%$ for gastric non-cardia adenocarcinoma throughout the study period and increased from 12 to $18 \%$ for cardia adenocarcinoma. Concurrently, the proportion of patients who underwent resectional surgery decreased from 49 to $38 \%$ for non-cardia adenocarcinoma and from 48 to $33 \%$ for cardia adenocarcinoma. The relative postoperative 5-year survival increased from 33 to $44 \%$ for non-cardia adenocarcinoma and from 21 to $43 \%$ for cardia adenocarcinoma, whereas in nonoperated patients it decreased from 3 to $2 \%$ in non-cardia adenocarcinoma and increased from 3 to $5 \%$ in cardia adenocarcinoma. Poor

(C) The Author(s) 2018

First Received: 13 March 2018;

Published Online: 9 July 2018

J. Lagergren, $\mathrm{PhD}$

e-mail: jesper.lagergren@ki.se prognostic factors were higher tumor stage, older age, and more comorbidity.

Conclusions. Despite decreasing resectional rates, the 5-year overall survival has remained unchanged for gastric non-cardia adenocarcinoma and improved for cardia adenocarcinoma over the last two decades in Sweden and is now similar for these sublocations. The postoperative survival has improved for both sublocations, but particularly for cardia adenocarcinoma.

Gastric cancer is the fifth most common cancer and the second most common cancer-related death globally. ${ }^{1}$ Adenocarcinoma is the dominant histologic type, accounting for $>95 \%$ of all gastric cancers. ${ }^{2}$ Gastric adenocarcinoma can be classified into two topographical subgroups, i.e., noncardia and cardia, because these tumors have different incidence patterns, etiology and prognosis. ${ }^{3-7}$ The incidence of gastric non-cardia adenocarcinoma has steadily decreased over the past decades, while it has increased for gastric cardia adenocarcinoma, at least until recently. ${ }^{8-11}$ The strongest risk factor for gastric non-cardia adenocarcinoma is Helicobacter pylori infection. ${ }^{3-5,12}$ Gastroesophageal reflux and obesity are the main risk factors for gastric cardia adenocarcinoma. ${ }^{12}$ Gastric adenocarcinoma has a poor overall prognosis; tumor stage and fitness (comorbidity and age) are the strongest prognostic factors but have great variability worldwide. ${ }^{1,3}$ The prognosis in non-cardia adenocarcinoma is generally better than that in cardia adenocarcinoma. ${ }^{13,14}$ However, an analysis of survival trends in Sweden in 1970-2008 identified a declining survival in gastric noncardia adenocarcinoma and an improving survival in gastric cardia adenocarcinoma. ${ }^{15}$ Surgery is the main curative treatment, and for locally advanced disease, oncological therapy is usually added to surgery. ${ }^{3}$ 
Assessing changes in survival over time is important in the evaluation of changes in detection and treatment of gastric adenocarcinoma. Sweden offers excellent opportunities to assess population-based and nationwide survival trends in cancer because all individuals in Sweden are since long registered for cancer and mortality in updated nationwide highly complete registries. This study assessed the survival trends in gastric non-cardia and cardia adenocarcinoma in patients having undergone resectional surgery and no such surgery in a population-based cohort study in Sweden.

\section{METHODS}

\section{Design}

This nationwide, Swedish, population-based cohort study examined the prognosis in patients diagnosed with gastric non-cardia adenocarcinoma and gastric cardia adenocarcinoma between 1990 and 2013 with follow-up until May 14, 2017. The data were collected from three well-established nationwide Swedish registries (presented below). The study was approved by the Regional Ethical Review Board in Stockholm, Sweden (diary number 2015/1916-31/1).

\section{Data Collection}

The patients with gastric adenocarcinoma were identified through data from the Swedish Cancer Registry. This registry was established in 1958 and has $98 \%$ completeness in the recording of gastric adenocarcinoma. ${ }^{16}$ The Cancer Registry provided accurate information regarding date of diagnosis, histological type and location, tumor stage, age at diagnosis, and sex. The 7th version of the International Classification of Diagnoses (ICD-7) was used for coding of cancer diagnoses and WHO/HS/CANC/24/24.1 for coding of histological type of cancer. Gastric non-cardia adenocarcinoma was coded as ICD-7 code $151.0,151.8$ or 151.9 combined with the histology code 096, and cardia adenocarcinoma was coded as ICD-7 code 151.1 combined with the histology code 096. Histologic types other than adenocarcinoma were excluded because they are not comparable in terms of treatment or prognosis. Tumor stage data were added in the Swedish Cancer Registry from June 2004 onwards and were based on the classification of the 6th edition of the TNM-staging system of the Union Internationale Contre le Cancer. ${ }^{17}$

Data regarding surgical tumor resection and comorbidities at the time of diagnosis were retrieved from the Swedish Patient Registry. This is a registry with a national completeness of above $99 \%$ and a positive predictive value of $99.6 \%$ for resectional surgery of upper gastrointestinal cancer. ${ }^{18,19}$ Resectional surgery included total gastrectomy or subtotal gastrectomy, coded according to the Swedish Surgical Codes, 6th edition as 4430, 4432, 4434, 4435 or 4411-4420, 4422, 4424-4426, or 4429. Comorbidity was defined according to the most updated version of the wellvalidated Charlson Comorbidity Index. ${ }^{20}$

Mortality was assessed from the Swedish Causes of Death Registry, which has virtually $100 \%$ complete information on date of death for all deceased Swedish residents from 1952 onwards. ${ }^{21}$

\section{Statistical Analysis}

Observed and relative survival was analyzed at 1 and 5 years following the diagnosis of gastric non-cardia adenocarcinoma or gastric cardia adenocarcinoma, analyzed separately. Observed survival with $95 \%$ confidence interval (CI) was estimated using the life-table method, where the event was defined as death from any cause, i.e., all-cause mortality. ${ }^{22}$ To assess disease-specific mortality, relative survival with $95 \%$ CIs was calculated as the ratio of the observed to the expected survival. The expected survival was derived from a matched cohort from the entire general Swedish population. The survival in the general Swedish population was available from the start of the study (1990) until end of 2015. The relative survival rates for years 2016 and 2017 were based on the mortality rates of 2015. The results were analyzed for all patients as well as stratified by resectional surgery (representing "curative treatment") and no such surgery (representing "palliative treatment").

The observed survival was further stratified by calendar periods (1990-1994, 1995-1999, 2000-2004, 2005-2009, and 2010-2013), age groups $(<60,60-69,70-79$, and $\geq 80$ years), sex (male and female), and comorbidity (Charlson Comorbidity Index score 0,1 , and $\geq 2$ ). Surgically treated patients were also stratified by tumor stage (0-I, II, and III-IV) from year 2005 onwards, when tumor stage data were of good quality and completeness according to a recent validation study from our group. ${ }^{23}$ To manage partial missing data for tumor stage $(19.5 \%$ for gastric non-cardia adenocarcinoma and $11.0 \%$ for cardia adenocarcinoma), both complete case analysis and multiple imputation analysis were used. The number of imputed datasets were 20 and the monotone logistic method in PROC MI in SAS was used under the assumption that missing data were missing at random. ${ }^{24}$ The variables included in the imputation were 5-year mortality, tumor stage (0-I, II, or III-IV), calendar period (2005-2009 or 2010-2013), age (continuous), sex (male or female), and Charlson Comorbidity Index score $(0,1$, or $\geq 2)$. PROC 

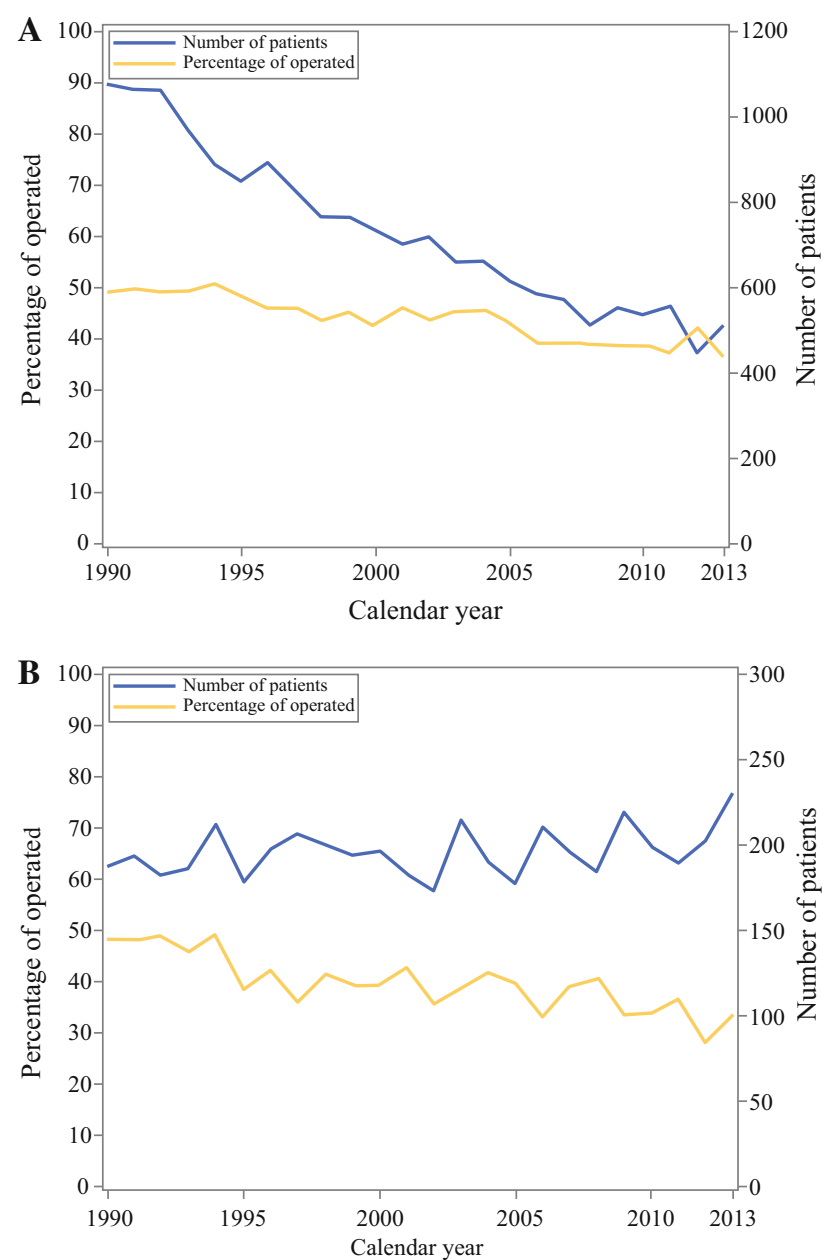

FIG. 1 The graphs show number of gastric non-cardia adenocarcinoma (a) and gastric cardia adenocarcinoma (b) patients diagnosed in Sweden by year from 1990 to 2013 (with follow-up until 2017). The curves show the number of patients diagnosed with cancer (solid line) and proportion of patients undergoing surgery (dotted line)

MIANALYZE in SAS was used to combine the results from the analyses of the 20 datasets.

To also examine prognostic factors, Cox regression modelling was used to calculate crude and adjusted hazard ratios (HR) of mortality with $95 \%$ CIs for each of the stratification variables above, which were thus considered potential prognostic factors. The estimates for each of these potential prognostic factors were adjusted for the other factors, using the same categorization as presented above.

An experienced biostatistician (FM) conducted all data management and statistical analyses according to a detailed and pre-defined study protocol. All analyses were conducted using the SAS Statistical Package (version 9.4, SAS Institute Inc., Gary, NC).

\section{RESULTS}

\section{Patients}

This study included 17,491 patients diagnosed with noncardia adenocarcinoma and 4698 with cardia adenocarcinoma (Table 1). Men were slightly overrepresented in patients with non-cardia adenocarcinoma (58\%) and strongly so in patients with cardia adenocarcinoma (76\%; Table 2).

\section{Resectional Surgery}

Surgical resection was conducted in 7828 (45\%) of all patients with gastric non-cardia adenocarcinoma and in 1855 (39\%) of those with cardia adenocarcinoma. Comparing patients who underwent surgery during the first (1990-1994) and last (2010-2013) calendar periods, the proportion of operated patients decreased from 49 to $38 \%$ for gastric non-cardia adenocarcinoma and from 48 to $33 \%$ for cardia adenocarcinoma (Table 1) (Fig. 1).

\section{Survival Trends in Gastric Non-cardia Adenocarcinoma}

The observed and relative survival data for gastric noncardia adenocarcinoma are presented in Table 1. Because the results for observed survival closely mirrored the relative survival, only the latter are presented here.

All Patients The 5-year relative survival rate in noncardia adenocarcinoma remained unchanged at $18 \%$ (95\% CI 17-20\%) throughout the study period (1990-2013 with follow-up until 2017; Table 1).

Surgically Treated Patients In patients who underwent resectional surgery for non-cardia adenocarcinoma the 5 -year relative survival increased from $33 \%$ (95\% CI $31-35 \%$ ) to $44 \%$ (95\% CI 40-48\%) between the first and last calendar period (Table 1) (Fig. 2). Comparing the observed 5-year tumor-stage specific survival for calendar period 2005-2009 with 2010-2013, the survival increased from $56 \%$ (95\% CI 50-61) to 59\% (95\% CI 52-66) for stage 0-I tumors, from $34 \%$ (95\% CI 27-41) to 53\% (95\% CI 45-61) for stage II tumors, and from $11 \%$ (95\% CI $8-14)$ to $18 \%$ (95\% CI 13-23) for stage III-IV tumors (Table 3) (Fig. 3).

Nonoperated Patients Among nonoperated patients with gastric non-cardia adenocarcinoma, the 5-year relative survival decreased slightly from $3 \%(95 \%$ CI $2-4 \%)$ to $2 \%$ (95\% CI 1-3\%) between the first and last calendar period (Table 1) (Fig. 2). 

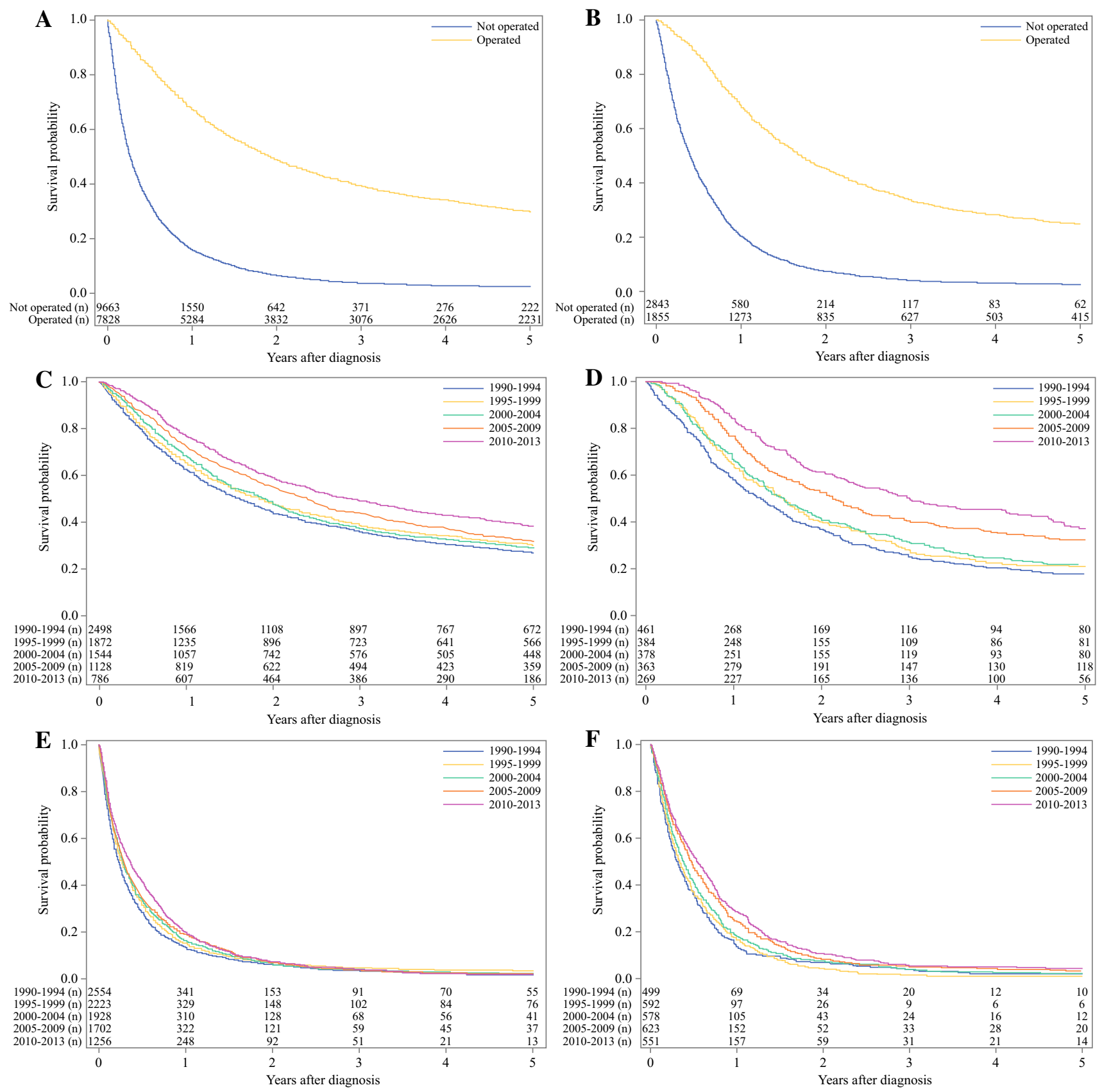

FIG. 2 Kaplan-Meier survival curves showing observed 5-year survival for gastric non-cardia adenocarcinoma (a) and gastric cardia adenocarcinoma (b) stratified by surgical treatment (yes or no). Patients undergoing tumor resection for gastric non-cardia

\section{Risk Factors for 5-year Mortality in Gastric Non- cardia Adenocarcinoma}

In the multivariable analysis of all patients with gastric non-cardia adenocarcinoma, the adjusted HR of mortality within 5 years of diagnosis was higher in earlier calendar periods (HR 1.11, 95\% CI 1.05-1.17, first vs. last calendar period), older age groups (HR 1.65, 95\% CI 1.56-1.74, age

adenocarcinoma (c) and gastric cardia adenocarcinoma (d) are further stratified by calendar periods. Survival of the patients not undergoing surgery for gastric non-cardia adenocarcinoma (e) and gastric cardia adenocarcinoma (f) are shown stratified by calendar period

$\geq 80$ vs. $<60$ years), and in patients with more comorbidity (HR $1.38,95 \%$ CI 1.31-1.45, comorbidity score $\geq 2$ vs. 0), whereas sex did not clearly influence the risk of mortality (Table 2). The risk factors for mortality within 5 years of diagnosis were the same in operated and nonoperated patients (Table 2). In addition, in surgically treated patients, where tumor stage was available, higher tumor stage was a poor prognostic factor (HR 3.97, 95\% CI 

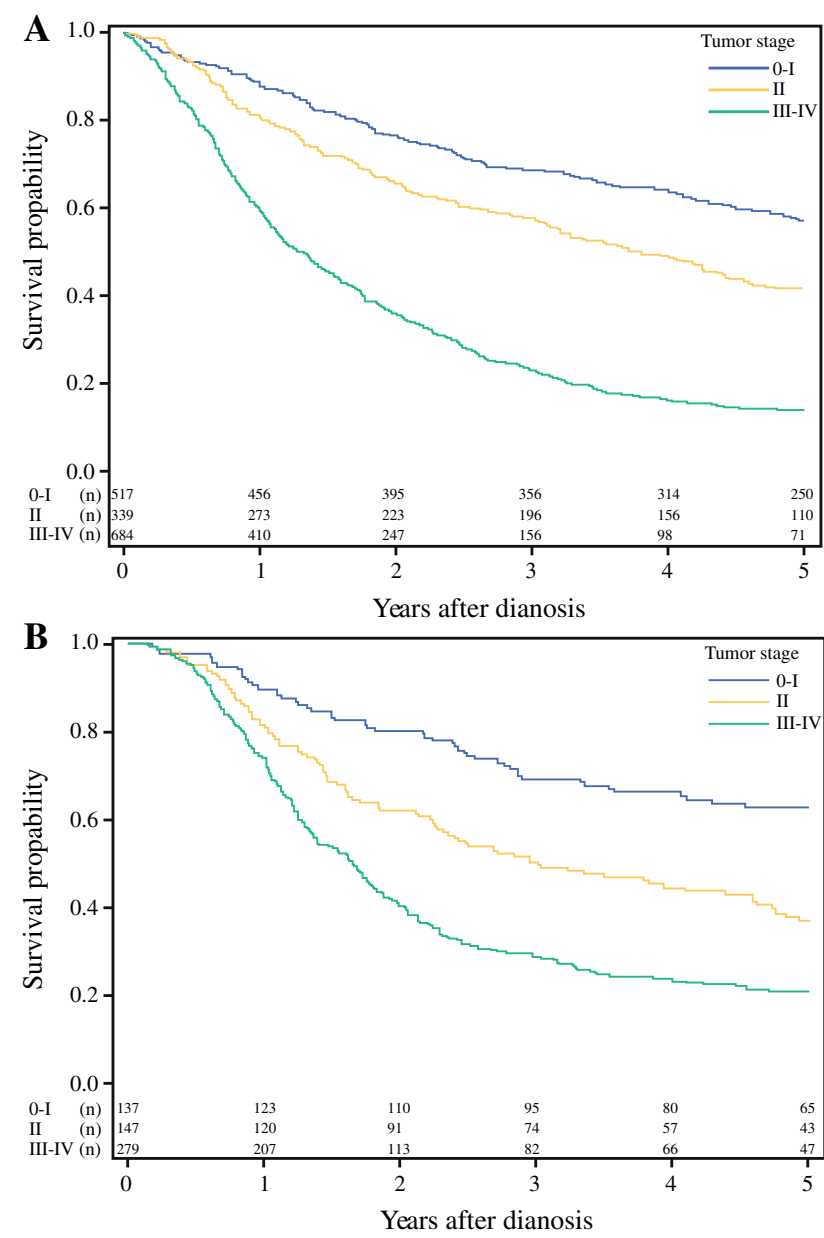

FIG. 3 Kaplan-Meier survival curve showing stage-specific observed 5-year survival for gastric non-cardia adenocarcinoma (a) and cardia adenocarcinoma (b) for patients operated 2005-2013

3.39-4.65, stage $0-$ I vs. III-IV). The results from the multiple imputation were similar to those in the complete case analysis (Tables 2, 3).

\section{Survival Trends in Gastric Cardia Adenocarcinoma}

The observed and relative survival data for gastric cardia adenocarcinoma were similar (Table 1), but only the latter are presented here.

All Patients The 5-year relative survival in gastric cardia adenocarcinoma increased from $12 \%$ (95\% CI 9.3-14\%) to $18 \%$ (95\% CI $15-21 \%$ ) between the first and the last calendar period (Table 1).

Surgically Treated Patients In patients who underwent resectional surgery for cardia adenocarcinoma, the 5-year relative survival increased from $21 \%$ (95\% CI 17-25\%) to $43 \%$ (95\% CI 37-50\%) between the first and the last calendar period (Table 1) (Fig. 2). Comparing the observed 5-year, tumor stage-specific survival in operated patients for the calendar period 2005-2009 with 2010-2013, the survival decreased from $65 \%$ (95\% CI 54-76\%) to $62 \%$ (95\% CI 50-74\%) for tumor stage 0-I, from 39\% (95\% CI $28-49 \%$ ) to $32 \%$ (95\% CI $21-47 \%$ ) for tumor stage II, but increased from $16 \%$ (95\% CI $10-22 \%$ ) to $28 \%$ (95\% CI 20-36\%) for tumor stage III-IV (Table 3) (Fig. 3).

Nonoperated Patients In nonoperated patients with cardia adenocarcinoma, the 5-year relative survival increased from $3 \%(95 \%$ CI $1-4 \%)$ to $5 \%(95 \%$ CI $3-7 \%)$ between the first and the last calendar period (Table 1) (Fig. 2).

\section{Risk Factors for 5-year Mortality in Gastric Cardia Adenocarcinoma}

In the multivariable analysis of all patients, operated patients, and nonoperated patients with gastric cardia adenocarcinoma, the prognostic factors were the same as those for gastric non-cardia adenocarcinoma, except for that females who underwent surgery had a slightly lower HR of 5-year mortality than operated males (HR $0.86,95 \%$ CI 0.75-0.99; Table 2).

\section{DISCUSSION}

This study indicates an unchanged overall survival in all patients with gastric non-cardia adenocarcinoma and an improved survival in all patients with cardia adenocarcinoma, but particularly in resected patients, during the last two decades in Sweden. These trends occurred despite of a gradually lower proportion of patients undergoing resectional surgery. In resected patients, the survival in noncardia adenocarcinoma increased in all tumor stages but only in more advanced tumor stages in cardia adenocarcinoma. Higher tumor stage, older age, and comorbidity were poor prognostic factors.

Strengths of this study include the population-based design, enabled by the Swedish personal identity numbers combined with high-quality and complete nationwide registries of cancer, treatment, and mortality. The sample size was large enough to permit analyses of time trends in subgroups of patients and to assess prognostic factors. A weakness is potential tumor misclassification, mainly regarding cardia adenocarcinoma. However, some level of misclassification is unavoidable in any study examining this tumor, and the Swedish Cancer Registry has a reasonably good accuracy in the recording of this tumor. ${ }^{16}$ The lack of some clinical variables, such as use of neoadjuvant or adjuvant treatment is a limitation. Use of neoadjuvant treatment could improve the survival. 


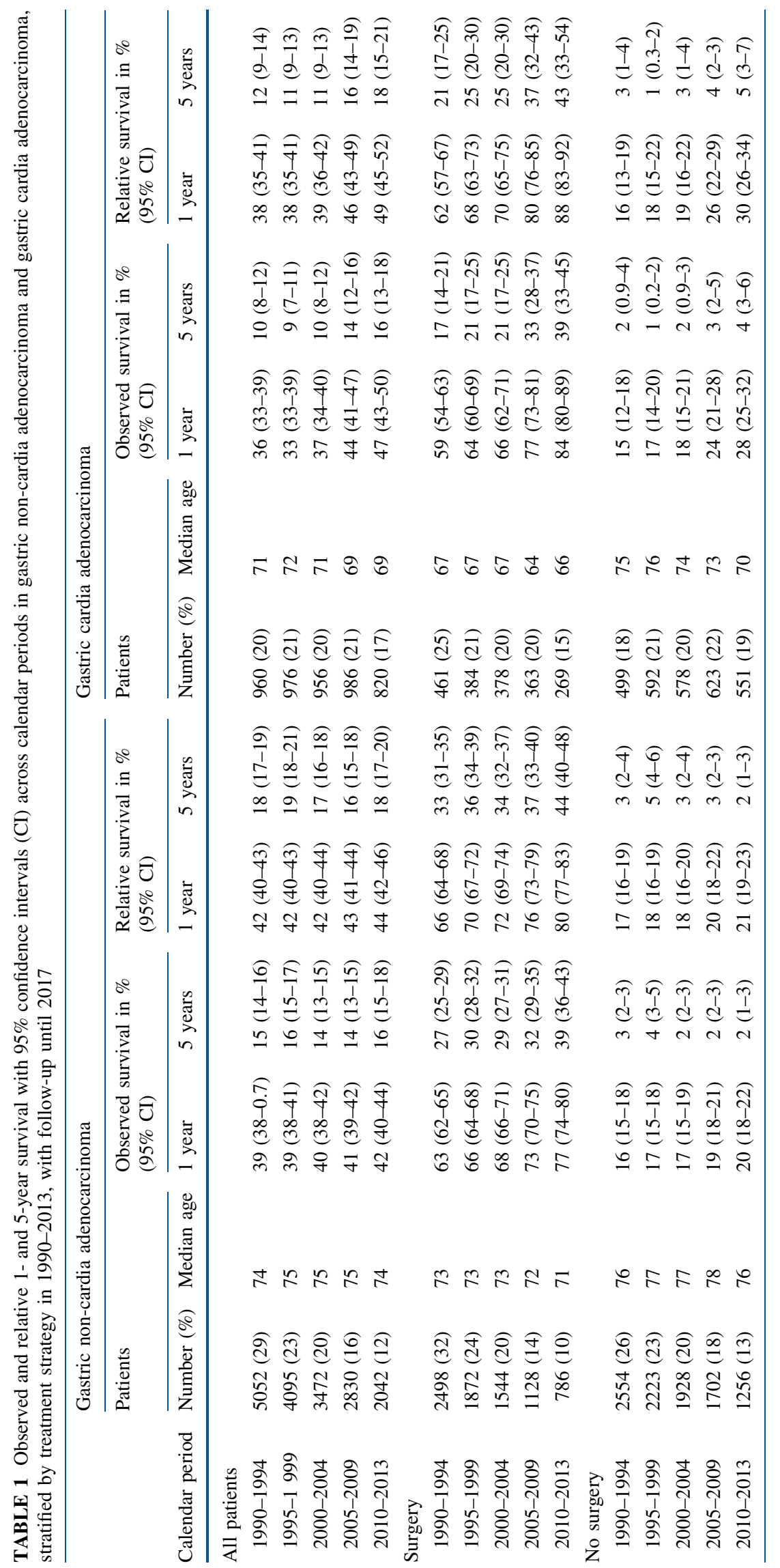


TABLE 2 Observed 5-year survival and adjusted hazard ratios (HR) with 95\% confidence intervals (CI) for gastric non-cardia adenocarcinoma and gastric cardia adenocarcinoma 1990-2017

\begin{tabular}{|c|c|c|c|c|c|c|c|}
\hline \multirow[t]{2}{*}{ Covariate } & \multirow[t]{2}{*}{ Category } & \multicolumn{3}{|c|}{ Gastric non-cardia adenocarcinoma } & \multicolumn{3}{|c|}{ Gastric cardia adenocarcinoma } \\
\hline & & $\begin{array}{l}\text { Number of } \\
\text { patients }(\%)\end{array}$ & $\begin{array}{l}\text { Observed 5-year } \\
\text { survival }(95 \% \mathrm{CI})\end{array}$ & $\operatorname{HR}(95 \% \mathrm{CI})^{\mathrm{a}}$ & $\begin{array}{l}\text { Number of } \\
\text { patients }\end{array}$ & $\begin{array}{l}\text { Observed 5-year } \\
\text { survival }(95 \% \mathrm{CI})\end{array}$ & $\mathrm{HR}(95 \% \mathrm{CI})^{\mathrm{a}}$ \\
\hline \multicolumn{8}{|l|}{ All patients } \\
\hline \multirow{5}{*}{$\begin{array}{l}\text { Calendar } \\
\text { period }\end{array}$} & 1990-1994 & $5052(29)$ & $15(14-16)$ & $1.11(1.05-1.17)$ & $960(20)$ & $10(8-12)$ & $1.31(1.18-1.45)$ \\
\hline & 1995-1999 & $4095(23)$ & $16(15-17)$ & $1.08(1.02-1.15)$ & $976(21)$ & $9(7-11)$ & $1.33(1.20-1.47)$ \\
\hline & 2000-2004 & $3472(20)$ & $14(13-15)$ & $1.09(1.03-1.16)$ & $956(20)$ & $10(8-12)$ & $1.25(1.13-1.38)$ \\
\hline & 2005-2009 & $2830(16)$ & $14(13-15)$ & $1.07(1.01-1.14)$ & $986(21)$ & $14(12-16)$ & $1.07(0.97-1.19)$ \\
\hline & 2010-2013 & $2042(12)$ & $16(15-18)$ & 1 (reference) & $820(17)$ & $16(13-18)$ & 1 (reference) \\
\hline \multirow[t]{4}{*}{ Age (years) } & $<60$ & $2438(14)$ & $23(21-25)$ & 1 (reference) & $963(26)$ & $18(16-20)$ & 1 (reference) \\
\hline & $60-69$ & $3417(20$ & $20(18-21)$ & $1.08(1.02-1.15)$ & $1238(32)$ & $15(13-17)$ & $1.10(1.01-1.21)$ \\
\hline & $70-79$ & $6168(35)$ & $16(15-17)$ & $1.18(1.12-1.24)$ & $1505(21)$ & $10(9-12)$ & $1.31(1.19-1.43)$ \\
\hline & $\geq 80$ & $5468(31)$ & $7(7-8)$ & 1.65 (1.56-1.74) & $992(21)$ & $3(2-4)$ & $1.99(1.80-2.20)$ \\
\hline \multirow[t]{2}{*}{ Sex } & Male & $10,132(58)$ & $15(14-16)$ & 1 (reference) & $3593(76)$ & $12(11-13)$ & 1 (reference) \\
\hline & Female & $7359(42)$ & $15(15-16)$ & $0.99(0.56-1.02)$ & $1105(24)$ & $11(9-13)$ & $1.04(0.97-1.12)$ \\
\hline \multirow{3}{*}{$\begin{array}{l}\text { Comorbidity } \\
\text { score }\end{array}$} & 0 & $9160(52)$ & $19(18-20)$ & 1 (reference) & $2653(56)$ & $14(13-15)$ & 1 (reference) \\
\hline & 1 & $5947(34)$ & $12(11-13)$ & $1.29(1.24-1.33)$ & $1405(30)$ & $10(8-11)$ & $1.0(1.12-1.29)$ \\
\hline & $\geq 2$ & $2384(14)$ & $9(7-10)$ & $1.38(1.31-1.45)$ & $640(14)$ & $5(3-6)$ & $1.38(1.26-1.51)$ \\
\hline \multicolumn{8}{|l|}{ Surgery } \\
\hline \multirow{5}{*}{$\begin{array}{l}\text { Calendar } \\
\text { period }\end{array}$} & 1990-1994 & $2498(32)$ & $27(25-29)$ & $1.46(1.32-1.62)$ & $461(25)$ & $17(14-21)$ & $2.08(1.73-2.51)$ \\
\hline & 1995-1999 & $1872(24)$ & $30(28-32)$ & $1.34(1.20-1.48)$ & $384(21)$ & $21(17-25)$ & $1.81(1.50-2-20)$ \\
\hline & 2000-2004 & $1544(20)$ & $29(27-31)$ & $1.37(1.23-1.52)$ & $378(20)$ & $21(17-25)$ & $1.72(1.42-2.09)$ \\
\hline & 2005-2009 & $1128(14)$ & $32(29-35)$ & $1.20(1.07-1.34)$ & $363(20)$ & $33(28-37)$ & $1.26(1.03-1.54)$ \\
\hline & 2010-2013 & $786(10)$ & $39(36-43)$ & 1 (reference) & $269(15)$ & $39(33-45)$ & 1 (reference) \\
\hline \multirow[t]{4}{*}{ Age (years) } & $<60$ & $1296(17)$ & $39(37-42)$ & 1 (reference) & $516(28)$ & $30(26-34)$ & 1 (reference) \\
\hline & $60-69$ & $1763(23)$ & $35(33-37)$ & $1.10(1.01-1.21)$ & $617(33)$ & $26(22-29)$ & $1.14(0.99-1.31)$ \\
\hline & $70-79$ & $3109(40)$ & $29(27-31)$ & $1.25(1.15-1.35)$ & $601(32)$ & $22(19-25)$ & $1.24(1.07-1.42)$ \\
\hline & $\geq 80$ & $1660(21)$ & $20(18-22)$ & $1.61(1.47-1.76)$ & $121(7)$ & $15(9-22)$ & $1.60(1.28-1.99)$ \\
\hline \multirow[t]{2}{*}{ Sex } & Male & 4597 (59) & $29(28-31)$ & 1 (reference) & $1491(80)$ & $24(22-26)$ & 1 (reference) \\
\hline & Female & $3231(41)$ & $31(29-33)$ & $0.96(0.91-1.02)$ & $364(20)$ & $29(25-34)$ & $0.86(0.75-0.99)$ \\
\hline \multirow{3}{*}{$\begin{array}{l}\text { Comorbidity } \\
\text { score }\end{array}$} & 0 & $4578(58)$ & $35(33-36)$ & 1 (reference) & $1211(65)$ & $27(25-30)$ & 1 (reference) \\
\hline & 1 & $2445(31)$ & $25(23-26)$ & $1.28(1.20-1.35)$ & $480(26)$ & $24(20-28)$ & $1.17(1.03-1.32)$ \\
\hline & $\geq 2$ & 805 (10) & $21(18-24)$ & $1.41(1.29-1.54)$ & $164(9)$ & $11(6-16)$ & $1.60(1.34-1.91)$ \\
\hline \multicolumn{8}{|l|}{ No surgery } \\
\hline \multirow{5}{*}{$\begin{array}{l}\text { Calendar } \\
\text { period }\end{array}$} & 1990-1994 & $2554(26)$ & $3(2-3)$ & $1.22(1.14-1.30)$ & 499 (18) & $2(0.9-4)$ & $1.41(1.24-1.59)$ \\
\hline & 1995-1999 & $2223(23)$ & $4(3-5)$ & $1.12(1.04-1.20)$ & $592(21)$ & $1(0.2-2)$ & $1.41(1.25-1.59)$ \\
\hline & 2000-2004 & $1928(20)$ & $2(2-3)$ & $1.10(1.02-1.18)$ & $578(20)$ & $2(0.9-3)$ & $1.26(1.12-1.42)$ \\
\hline & 2005-2009 & $1702(18)$ & $2(2-3)$ & $1.07(0.99-1.15)$ & $623(22)$ & $3(2-5)$ & $1.09(0.97-1.23)$ \\
\hline & 2010-2013 & $1256(13)$ & $2(1-3)$ & 1 (reference) & $551(19)$ & $4(3-6)$ & 1 (reference) \\
\hline \multirow[t]{4}{*}{ Age (years) } & $<60$ & $1142(12)$ & $4(3-5)$ & 1 (reference) & $447(16)$ & $4(2-6)$ & 1 (reference) \\
\hline & $60-69$ & $1654(17)$ & $4(3-4)$ & $1.07(0.99-1.15)$ & $621(22)$ & $3(2-5)$ & $1.02(0.90-1.16)$ \\
\hline & $70-79$ & 3059 (32) & $3(2-4)$ & $1.15(1.07-1.23)$ & $904(32)$ & $3(2-4)$ & $1.10(0.97-1.23)$ \\
\hline & $\geq 80$ & 3808 (39) & $1(1-2)$ & $1.17(1.09-1.26)$ & $871(31)$ & $1(0.5-2)$ & $1.18(0.98-1.17)$ \\
\hline \multirow[t]{2}{*}{ Sex } & Male & $5535(57)$ & $3(2-3)$ & 1 (reference) & $2102(74)$ & $3(1-3)$ & 1 (reference) \\
\hline & Female & $4128(43)$ & $2(2-3)$ & $0.98(0.94-1.02)$ & $741(26)$ & $2(1-3)$ & 1.07 (0.98-1.17) \\
\hline
\end{tabular}


TABLE 2 continued

\begin{tabular}{|c|c|c|c|c|c|c|c|}
\hline \multirow[t]{2}{*}{ Covariate } & \multirow[t]{2}{*}{ Category } & \multicolumn{3}{|c|}{ Gastric non-cardia adenocarcinoma } & \multicolumn{3}{|c|}{ Gastric cardia adenocarcinoma } \\
\hline & & $\begin{array}{l}\text { Number of } \\
\text { patients }(\%)\end{array}$ & $\begin{array}{l}\text { Observed 5-year } \\
\text { survival }(95 \% \mathrm{CI})\end{array}$ & $\operatorname{HR}(95 \% \mathrm{CI})^{\mathrm{a}}$ & $\begin{array}{l}\text { Number of } \\
\text { patients }\end{array}$ & $\begin{array}{l}\text { Observed 5-year } \\
\text { survival }(95 \% \mathrm{CI})\end{array}$ & $\operatorname{HR}(95 \% \mathrm{CI})^{\mathrm{a}}$ \\
\hline \multirow{3}{*}{$\begin{array}{l}\text { Comorbidity } \\
\text { score }\end{array}$} & 0 & $4582(47)$ & $4(3-5)$ & 1 (reference) & $1442(51)$ & $3(2-4)$ & 1 (reference) \\
\hline & 1 & $3502(36)$ & $3(1-4)$ & $1.18(1.13-1.23)$ & $925(33)$ & $2(2-3)$ & $1.10(1.01-1.20)$ \\
\hline & $\geq 2$ & $1579(16)$ & $2(1-3)$ & $1.11(1.05)$ & $476(17)$ & $2(1-4)$ & $1.08(0.97-1.20)$ \\
\hline
\end{tabular}

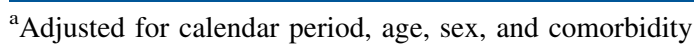

However, few patients have definite chemoradiotherapy for gastric adenocarcinoma and the palliative strategy in the vast majority of nonoperated patients is mirrored by the very low 5-year survival rates. We had no data on hospital volume, but the ongoing centralization of gastric cancer surgery probably contributes to the positive trends. Data on tumour stage were partially missing in $19.5 \%$ of patients with non-cardia adenocarcinoma and in $11.0 \%$ in those with cardia adenocarcinoma. However, complete case analysis and multiple imputation analysis provided similar results, indicating that the missing data did not influence the findings.

Earlier studies examining the time trends in long-term prognosis in gastric adenocarcinoma report different results. A European registry-based study (EUROCARE-5) showed an overall slightly increased 5-year relative survival rate from 23 to $25 \%$ for all gastric cancer in 1999-2007 in Europe. ${ }^{13}$ A recent registry-based study of 150,700 patients diagnosed with gastric cancer in the United States found a slight improvement in the 5-year age-standardized survival from $26 \%$ in 2001-2003 to $29 \%$ in 2004-2009. ${ }^{25}$ A Korean registry-based study suggested greatly improving relative 5-year survival rates for all gastric cancers from $43 \%$ in $1993-1995$ to $74 \%$ in 2010-2014. ${ }^{26}$ Unfortunately, none of these three studies separated non-cardia and cardia cancer or excluded other histological types than adenocarcinoma. On the other hand, a Dutch population-based study found that the overall 5 -year survival decreased from 22 to $14 \%$ for gastric noncardia adenocarcinoma and remained stable at $10 \%$ for cardia adenocarcinoma between 1990 and 2006. ${ }^{14}$

In contrast to the findings of the present study, which found a similar prognosis in non-cardia adenocarcinoma and cardia adenocarcinoma during the last study period, the majority of existing data globally, indicate a clearly lower 5 -year survival for gastric cardia adenocarcinoma compared to gastric non-cardia adenocarcinoma..$^{13,27,28}$ This discrepancy might be at least partly explained by the fact that the present study included a more recent time period than earlier studies. With a continued unchanged survival for gastric non-cardia adenocarcinoma and increasing survival for cardia adenocarcinoma, the reported survival rates will eventually become more equal also in other studies examining more recent data.

This study showed a clear decline in the proportion of patients undergoing resectional surgery in both gastric noncardia and cardia adenocarcinoma, possibly explained by stricter selection of patients for surgery which might be driven by developments in diagnostic tools. It also showed a substantially improved prognosis over time for those who underwent surgery, likely explained by the better selection of patients for surgery, general introduction of multidisciplinary team meetings, centralization of services to fewer surgical centers, and a more widespread use of neo-adjuvant chemotherapy. ${ }^{29,30}$ The fact that the prognosis in all patients (operated and nonoperated combined) with noncardia adenocarcinoma has been stable and even improved in cardia adenocarcinoma indicates that the selection for surgery is reasonably accurate. This is a slightly different trend from what was seen in the previous Swedish study examining survival trends in 1970-2008, where patients with non-cardia adenocarcinoma had a worsening prognosis. This change in survival is likely due to the improved prognosis for those operated as mentioned above. In Sweden, the surgical treatment of cardia adenocarcinoma has been increasingly centralized to larger centers, but this development has been slower for gastric non-cardia adenocarcinoma. The lack of improvement in non-cardia adenocarcinoma overall survival whilst the corresponding prognosis has improved in cardia adenocarcinoma indicates a need for further centralization for non-cardia adenocarcinoma. The on-going centralization in Sweden has led to that number of centers conducting surgery for gastric cardia cancer declined from more than 20 in 2007 to 7 in 2016, and from more than 50 in 2007 to 15 in 2016 for gastric non-cardia cancer.

More advanced tumor stage, earlier calendar period, older age, and more comorbidity were poor prognostic risk factors for both gastric non-cardia and cardia adenocarcinoma, which was expected and in line with previous research. 


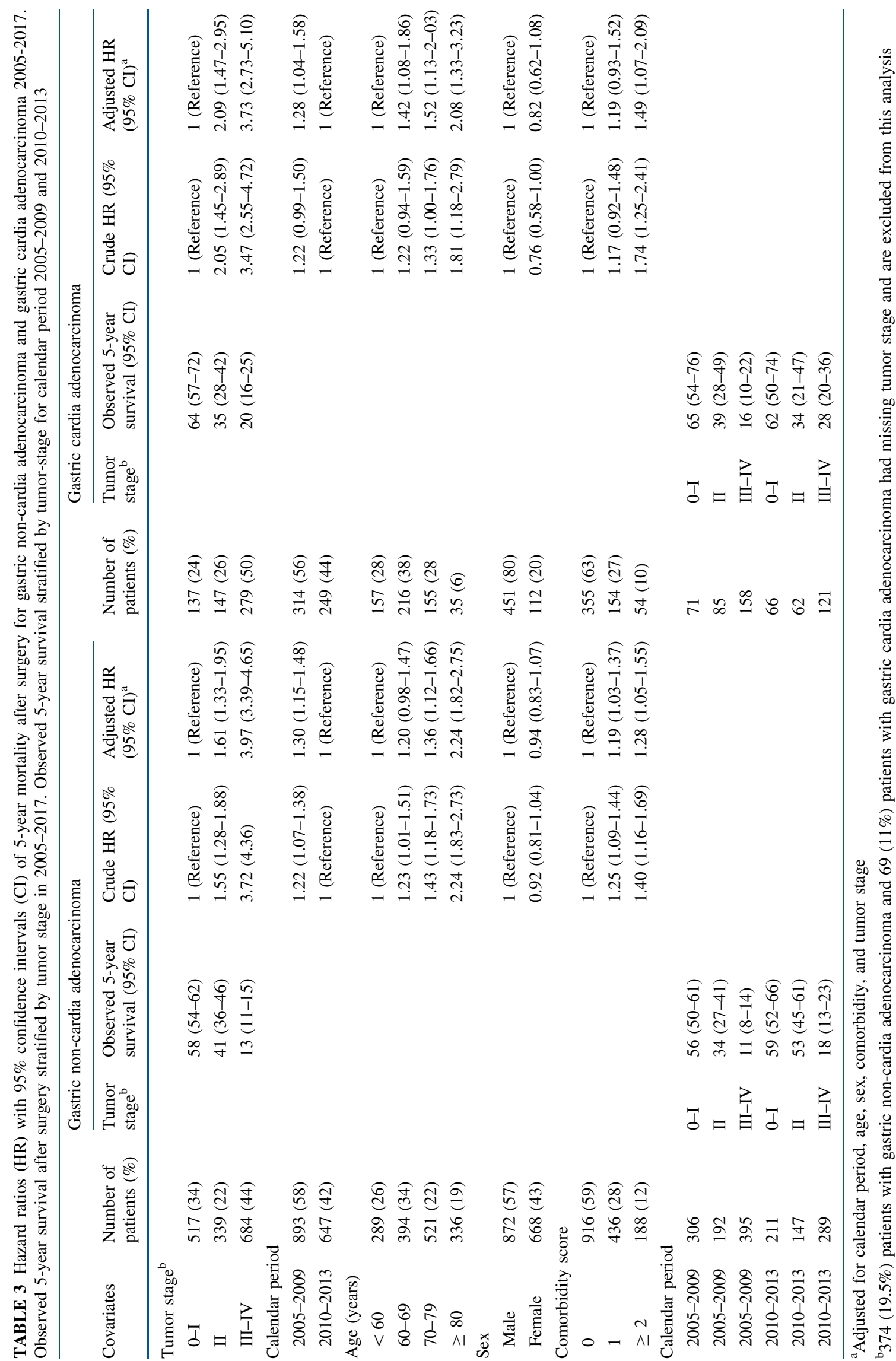


In conclusion, this population-based and nationwide Swedish study with long and complete follow-up indicates that the overall prognosis in patients with gastric non-cardia adenocarcinoma has remained stable during the last two decades, whereas the prognosis in gastric cardia adenocarcinoma has improved, and the 5-year survival is now equal between these groups in Sweden. For the decreasing proportion of patients who underwent resectional surgery, the survival has improved substantially, likely due to a more strict selection of patients for surgery. The lack of improvement in overall prognosis in non-cardia adenocarcinoma indicates a need for increased centralization to larger centers of these patients, similar to what has taken place for gastric cardia adenocarcinoma.

FUNDING This work was supported by the Swedish Research Council and the Swedish Cancer Society. The funding sources had no role in the design and conduct of the study; collection, management, analysis, and interpretation of the data; preparation, review, or approval of the manuscript; or decision to submit the manuscript for publication.

OPEN ACCESS This article is distributed under the terms of the Creative Commons Attribution 4.0 International License (http://crea tivecommons.org/licenses/by/4.0/), which permits unrestricted use, distribution, and reproduction in any medium, provided you give appropriate credit to the original author(s) and the source, provide a link to the Creative Commons license, and indicate if changes were made.

\section{REFERENCES}

1. Balakrishnan M, George R, Sharma A, Graham DY. Changing trends in stomach cancer throughout the world. Curr Gastroenterol Rep. 2017;19(8):36.

2. Ferlay J, Shin HR, Bray F, Forman D, Mathers C, Parkin DM. Estimates of worldwide burden of cancer in 2008: GLOBOCAN 2008. Int J Cancer. 2010;127(12):2893-917.

3. Van Cutsem E, Sagaert X, Topal B, Haustermans K, Prenen H (2016) Gastric cancer. Lancet (London, England) 388(10060):2654-64.

4. Ladeiras-Lopes R, Pereira AK, Nogueira A, et al. Smoking and gastric cancer: systematic review and meta-analysis of cohort studies. Cancer Causes Control CCC. 2008;19(7):689-701.

5. Zali H, Rezaei-Tavirani M, Azodi M. Gastric cancer: prevention, risk factors and treatment. Gastroenterol Hepatol Bed Bench. 2011;4(4):175-85.

6. Colquhoun A, Arnold M, Ferlay J, Goodman KJ, Forman D, Soerjomataram I. Global patterns of cardia and non-cardia gastric cancer incidence in 2012. Gut. 2015;64(12):1881-88.

7. HACC group. Gastric cancer and Helicobacter pylori: a combined analysis of 12 case control studies nested within prospective cohorts. Gut. 2001;49(3):347-53

8. Amini N, Spolverato G, Kim Y, et al. Clinicopathological features and prognosis of gastric cardia adenocarcinoma: a multiinstitutional US study. J Surg Oncol. 2015;111(3):285-92.

9. Arnold M, Karim-Kos HE, Coebergh JW, et al. Recent trends in incidence of five common cancers in 26 European countries since 1988: analysis of the European Cancer Observatory. Eur J Cancer (Oxford, England: 1990) 2015;51(9):1164-87.
10. Ang TL, Fock KM. Clinical epidemiology of gastric cancer. Singap Med J. 2014;55(12):621-28.

11. Carcas LP. Gastric cancer review. J Carcinog. 2014;13:14.

12. de Martel C, Forman D, Plummer M. Gastric cancer: epidemiology and risk factors. Gastroenterol Clin $N \mathrm{Am}$. 2013;42(2):219-40.

13. Anderson LA, Tavilla A, Brenner H, et al. Survival for oesophageal, stomach and small intestine cancers in Europe 1999-2007: results from EUROCARE-5. Eur J Cancer (Oxford, England: 1990) 2015;51(15):2144-57.

14. Dassen AE, Lemmens VE, van de Poll-Franse LV, et al. Trends in incidence, treatment and survival of gastric adenocarcinoma between 1990 and 2007: a population-based study in the Netherlands. Eur $J$ Cancer (Oxford, England: 1990) 2010;46(6):1101-10.

15. Lagergren J, Mattsson F. Diverging trends in recent populationbased survival rates in oesophageal and gastric cancer. PloS ONE. 2012;7(7):e41352.

16. Ekstrom AM, Signorello LB, Hansson LE, Bergstrom R, Lindgren A, Nyren O. Evaluating gastric cancer misclassification: a potential explanation for the rise in cardia cancer incidence. $J$ Natl Cancer Inst. 1999;91(9):786-90.

17. Amin MB, Greene FL, Edge SB, et al. The Eighth Edition AJCC Cancer staging manual: continuing to build a bridge from a population-based to a more "personalized" approach to cancer staging. CA Cancer J Clin. 2017;67(2):93-99.

18. Ludvigsson JF, Andersson E, Ekbom A, et al. External review and validation of the Swedish national inpatient register. $B M C$ Public Health 2011;11:450.

19. Lagergren K, Derogar M. Validation of oesophageal cancer surgery data in the Swedish Patient Registry. Acta Oncol. 2012;51(1):65-68.

20. Armitage JN, van der Meulen JH. Identifying co-morbidity in surgical patients using administrative data with the Royal College of Surgeons Charlson Score. Br J Surg. 2010;97(5):772-81.

21. Swedish Causes of Death Registry: Bortfall och kvalitet i dödsorsaksregistret. 2010.

22. Cutler SJ, Ederer F. Maximum utilization of the life table method in analyzing survival. J Chronic Dis. 1958;8(6):699-712.

23. Brusselaers N, Vall A, Mattsson F, Lagergren J. Tumour staging of oesophageal cancer in the Swedish Cancer Registry: a nationwide validation study. Acta Oncol (Stockholm, Sweden). 2015;54(6):903-8.

24. Little RJA, Rubin DB. Statistical analysis with missing data. Chicester: Wiley; 2016.

25. Jim MA, Pinheiro PS, Carreira H, Espey DK, Wiggins CL, Weir HK. Stomach cancer survival in the United States by race and stage (2001-2009): findings from the CONCORD-2 study. Cancer. 2017;123 Suppl 24:4994-5013.

26. Jung KW, Won YJ, Oh CM, Kong HJ, Lee DH, Lee KH. Cancer statistics in Korea: incidence, mortality, survival, and prevalence in 2014. Cancer Res Treat. 2017;49(2):292-305.

27. Zheng $\mathrm{L}, \mathrm{Wu} \mathrm{C}, \mathrm{Xi}$ P, et al. The survival and the long-term trends of patients with gastric cancer in Shanghai, China. BMC Cancer. 2014; 14:300.

28. Zhao J, Zhao J, Du F, et al. Cardia and non-cardia gastric cancer have similar stage-for-stage prognoses after R0 resection: a largescale, multicenter study in China. $J$ Gastrointest Surg. 2016;20(4):700-7.

29. Young JA, Shimi SM, Kerr L, McPhillips G, Thompson AM. Reduction in gastric cancer surgical mortality over 10 years: an adverse events analysis. Ann Med Surg (2012). 2014;3(2):26-30.

30. Nelen SD, Heuthorst L, Verhoeven RHA, et al. Impact of centralizing gastric cancer surgery on treatment, morbidity, and mortality. J Gastrointest Surg. 2017. 